\title{
DIAGNOSTIC ACCURACY OF FROZEN SECTION IN DETECTING MALIGNANT BRAIN TUMORS TAKING HISTOPATHOLOGY AS GOLD STANDARD.
}

1. FCPS (Neurosurgery) Consultant Neurosurgeon Aga Khan University Hospital, Karachi.

2. FCPS (Neurosurgery)

Assistant Professor of Neurosurgery Dow University of Health Sciences, OJHA Campus, Karachi.

3. FCPS (Neurosurgery) Instructor Neurosurgery Aga Khan University Hospital, Karachi.

4. FRCS-SN, FEBNS, FCPS (Neurosurgery) Senior Instructor Neurosurgery Shaukat Khanum Memorial Cance Hospital and Research Center. Lahore.

Correspondence Address:

Dr. Saad Akther Khan Department of Neurosurgery

B82 Block 15 Gulshan-e-lqbal Karachi Pakistan.

dr.saadbinanis@gmail.com

Article received on:

19/06/2019

Accepted for publication:

$16 / 05 / 2020$

\begin{abstract}
Saad Akhter Khan', Badar Uddin Ujjan², Naveed Zaman Akhunzada ${ }^{3}$, Saad Bin Anis ${ }^{4}$
\end{abstract}
\begin{abstract}
Objectives: To evaluate the diagnostic accuracy of frozen section in detecting malignant gliomas, taking histopathology as gold standard. Study Design: Cross-Sectional study. Setting: Neurosurgery Department, Aga Khan University Hospital, Karachi. Period: From March 2018 to Jan 2019. Material \& Methods: Through consecutive sampling technique, total 100 specimens from patients suspected of malignant gliomas on MRI brain with contrast, who were admitted in the neurosurgery department for elective tumor surgery were included. Intraoperatively, the specimen from the lesion identified on imaging through neuronavigation was taken and sent to histopathology department for frozen section analysis. The histopathology consultant was pre-informed about the case and probable time of receiving the specimen. The specimen for frozen section was sent in a dried container without formalin. Once received in pathology department, the tissue is rapidly cooled through a cryostat which converts tissue water into the ice and makes the tissue rigid for cutting into slices and viewing under the microscope for identifying the neoplastic tissue. The consultant histopathologist was request to provide frozen section report immediately and to keep the remaining specimen for definitive histopathology reporting as well. Data of malignancy on both Frozen Section and formal histopathology report was noted and comparison was done. Results: Mean age of the patients was $36.7 \pm 8.76$ years. There were $64(64 \%)$ male patients and $36(36 \%)$ female patients. Diagnostic accuracy of frozen section taking histopathology as a gold standard shows that sensitivity was found to be $83.3 \%$, specificity $84.4 \%$, Positive predictive value (PPV) $71.4 \%$ and negative predictive value (NPV) $91.5 \%$ \& Overall diagnosis accuracy was found $96.6 \%$. Conclusion: The Diagnostic accuracy of frozen section (FS) in detection of brain malignant gliomas was found to be satisfactory. It has a diagnostic accuracy of $96.9 \%$, sensitivity $83.3 \%$, specificity $84.4 \%$, Positive predictive value (PPV) $71.4 \%$ and negative predictive value (NPV) $91.5 \%$.
\end{abstract}

Key words: Diagnostic Accuracy, Frozen Section, Histopathology, Malignant Lesions.

Article Citation: Khan SA, Ujjan Badar Uddin, Akhunzada NZ, Anis SB. Diagnostic accuracy of frozen section in detecting malignant brain tumors taking histopathology as gold standard. Professional Med J 2020; 27(9):1814-1817. DOI: 10.29309/TPMJ/2020.27.09.3835

\section{INTRODUCTION}

Despite appreciating advancements in neuroradiology techniques, proper planning in neurology procedures is still dependent on histopathology reporting. ${ }^{1}$ The pathologist role is very important during neurology procedures; it helps to guide neuro-surgeons for on-going neurosurgery especially involving the tumors. Pathologists helpin differentiating theinflammatory masses from tumors and high grade tumors with cystic components. ${ }^{2,3}$ Frozen section (FS) have a very vital role for decision making of patients with neoplastic versus non-neoplastic neurological lesions. Since FS introduction, this technique has got widespread and rapid acceptance. ${ }^{4}$ FS provides easy and quick pathological information to the operating surgeons while the patient is still on operating table. The specimen for frozen section is sent in a dried container without formalin. Once received in pathology department, the tissue is rapidly cooled through a cryostat which converts tissue water into the ice and makes the tissue rigid for cutting into slices and viewing under the microscope for identifying the neoplastic tissue. The tissue structure is well preserved by dried cooling, thus providing better 
visualization of stroma and tumors. ${ }^{5}$

The ultimate purpose of FS is to provide accurate information in a shorter time to the surgeons to make immediate decision regarding nature of lesion, the extent and adequacy of resection thereby preventing the need of reoperations. ${ }^{6,7}$

The neuro-surgeon main confidence on FS is its diagnostic accuracy. So FS are routinely compared to the permanent sections to evaluate their diagnostic accuracy. This helps to evaluate discrepancies and deficiencies in FS reporting that may occur due to sampling errors, or interpretation errors. ${ }^{8}$ Correction of these errors helps to improve of diagnostic accuracy of FS. Therefore it is recommended to do periodic review of accuracy in histopathology departments. ${ }^{9}$

In present study we aimed to evaluate the diagnostic accuracy of frozen section in detecting malignant brain tumors taking histopathology as gold standard.

\section{MATERIAL \& METHODS}

In this cross-sectional study a total number of 100 specimens of patients who were suspected of brain tumor on MRI brain with contrast and were admitted in the neurosurgery department for elective tumor surgery, were included. Diagnosed cases of brain tumor who came with recurrence, patients with already reported tumor on histopathology, and patients with metastasis, arterio-venous malformations, abscesses, chronic granulomatous inflammation, lipomas, and tumours of the scalp were also excluded from the study. The study duration was from March-2018 to Jan-2019.

Intraoperatively, the specimen were sent to histopathology department. The consultant histopathologist was request to provide frozen section report immediately and to keep the remaining specimen for histopathology reporting as well. Data of malignancy on both FS and histopathology report was noted and compared.

Data regarding patient's age, gender, as well as FS and histopathology reporting was collected and entered in SPSS v23. Software for further analysis. $2 \times 2$ contingency table was tabulated for calculation of diagnostic accuracy of FS against histopathology reporting.

\section{RESULTS}

Mean age of the patients was $36.7 \pm 8.76$ years. There were 64 (64\%) male patients and 36 (36\%) female patients. Frozen section findings showed that Malignant Glioma was found in $\mathbf{5 6}$ (37\%) patients. While histopathology findings revealed Malignant Glioma in $48(31.7 \%)$ patients. Diagnostic accuracy of Frozen Section taking histopathology as a gold standard shows that sensitivity was found to be $81.25 \%$, specificity 83.82\%, PPV $70.27 \%$ and NPV $90.47 \%$ and overall diagnostic accuracy was $83 \%$ (Table-I).

\begin{tabular}{|l|c|c|c|}
\hline \multicolumn{1}{|c|}{$\begin{array}{l}\text { Frozen } \\
\text { Section }\end{array}$} & Positive & Negative & \multirow{2}{*}{ Total } \\
\hline Positive & 26 & 11 & 37 \\
\hline Negative & 06 & 57 & 63 \\
\hline Total & 32 & 68 & 100 \\
\hline $\begin{array}{l}\text { Sensitivity }=(26 \div 32) \times 100=81.25 \% \\
\text { Specificity }=(57 \div 55+11\}) \times 100=83.82 \% \\
\text { Positive predictive value }=(26 \div 37) \times 100=70.27 \% \\
\text { Negative predictive value }=(57 \div 63) \times 100=90.47 \% \\
\text { Diagnostic Accuracy }=(83 \div 100) \times 100=83 \%\end{array}$ \\
Table-I. $\mathbf{2} \times \mathbf{2}$ Contingency table for calculation \\
of diagnostic accuracy of frozen section (FS) \\
for diagnosis of malignant neoplasm taking \\
histopathology as gold standard.
\end{tabular}

\section{DISCUSSION}

Frozen section (FS) reporting provides information regarding primary diagnosis intra-operatively and help the surgeon to decide appropriate surgical options. It gives important information like either the biopsy is from appropriate area, and adequacy of the specimen taken to make final diagnosis. ${ }^{10}$ However, interpretation of FS is not an easy challenge for histopathologists. There are many factors which can limit the diagnosis such as very fragile nature of brain tissues, inappropriate specimen volume, extreme vascularity, necrosis and unconventional cellular morphology. Moreover, surgeons also use cautery for tumor dissection that can also alter tumor morphology due to burning trauma. ${ }^{11}$ Experience of consultant, 
and failure to recognize technical errors are also factors leading to misdiagnosis. ${ }^{11}$ So, the diagnosis of brain tumors is always based on a combination of clinical assessment, radiological findings and histopathological reporting.

CNS tumors are a major health concern because of increasing frequency, high morbidity, high mortality and poor prognosis. These neoplasms comprise $2 \%$ of all cancers and in children is the second most common type of cancer. ${ }^{12,13}$

Brain tumor is highly aggressive among all malignancies, the grade IV gliomas are among the worst prognosis cases, with a median survival of only 12 months, while only $4 \%$ patients have survival of more than 5 years after diagnosis. Prognosis is based on patients age and grading of tumor. ${ }^{14,15}$

In present study, sensitivity of FS was $81.25 \%$, specificity $83.82 \%$, PPV $70.27 \%$ and NPV $90.47 \%$ and overall diagnostic accuracy was $83 \%$.

A study by Khoddami et al. involving 273 specimens reported that FS reporting has accuracy of $99.5 \%$, sensitivity of $91.4 \%$, specificity $99.7 \%$, PPV of $88.4 \%$ and NPV of $99.8 \% .{ }^{16}$

Another study from Pakistan by Nasir-Ud-Din et al. reported that FS has a diagnostic accuracy of $88.9 \%$, sensitivity of $94.8 \%$, specificity $87.5 \%$, PPV of $98.6 \%$ and NPV $63.6 \% .{ }^{17}$

Higher the diagnostic accuracy of the frozen section, the lower are the chances of false negative or false positive results about the nature of specimen. Thus, with an acceptably high diagnostic accuracy, the surgeon can more confidently rely on the results of FS, with its direct impact on whether to proceed with surgery or be content with biopsy alone in case of eloquent area, deep seated or extensive and diffuse type tumors.

\section{CONCLUSION}

The Diagnostic accuracy of frozen section (FS) in detection of brain malignant gliomas was found to be satisfactory. Sensitivity of FS was $81.25 \%$, specificity $83.82 \%$, PPV $70.27 \%$ and NPV $90.47 \%$ and overall diagnostic accuracy was $83 \%$.

\section{Copyright $@ 16$ May, 2020.}

\section{REFERENCES}

1. Kim JE, Kim DG, Paek SH, Jung HW. Stereotactic biopsy for intracranial lesions: Reliability and its impact on the planning of treatment. Acta Neurochir. 2003; 145(7):547-54.

2. Sharifabadi $A H$, Haeri $H$, Zeinalizadeh $M$, Zargari $\mathrm{N}$, Razavi AE, Shahbazi $\mathrm{N}$, et al. Intraoperative consultation of central nervous system lesions. Frozen section, cytology or both? Pathol Res Pract. 2016; 212(3):179-84.

3. Bataille B, Delwail V, Menet E, Vandermarcq P, Ingrand $P$, Wager $M$, et al. Primary intracerebral malignant lymphoma: Report of $\mathbf{2 4 8}$ cases. J Neurosurg. 2000; 92(2):261-6.

4. Howanitz PJ, Hoffman GG, Zarbo RJ. The accuracy of frozen-section diagnoses in $\mathbf{3 4}$ hospitals. Arch Pathol Lab Med. 1990; 114(4):355-9.

5. Sharma S, Deb P. Intraoperative neurocytology of primary central nervous system neoplasia: A simplified and practical diagnostic approach. J Cytol. $2011 ; 28(4): 147-58$.

6. Mahe E, Ara S, Bishara M, Kurian A, Tauqir S, Ursani $\mathrm{N}$, et al. Intraoperative pathology consultation: Error, cause and impact. Can J Surg J Can Chir. 2013; 56(3):E13-8.

7. Shrestha S, Basyal R, Pathak TSS, Lee M, Dhakal H, Pun $\mathrm{C}$, et al. Comparative study of frozen section diagnoses with histopathology. Post-Graduate Med J NAMS. 2009; 9(02):1-5.

8. Jaafar $\mathrm{H}$. Intra-operative frozen section consultation: Concepts, applications and limitations. Malays J Med Sci. 2006; 13(1):4-12.

9. Raab SS, Tworek JA, Souers R, Zarbo RJ. The value of monitoring frozen section-permanent section correlation data over time. Arch Pathol Lab Med. 2006; 130(3):337-42.

10. Somerset HL, Kleinschmidt-DeMasters BK. Approach to the intraoperative consultation for neurosurgical specimens. Adv Anat Pathol. 2011; 18(6):446-9.

11. Rao S, Rajkumar A, Ehtesham M, Duvuru P. Challenges in neurosurgical intraoperative consultation. Neurol India. 2009; 57(4):464. 
12. Bhurgri $Y$. The role of cancer registration in National Cancer Control Pakistan. J Pak Med Assoc. 2004; 54(8):402-3.

13. Bhurgri Y, Bhurgri A, Hassan SH, Zaidi S, Rahim A, Sankaranarayanan $R$, et al. Cancer incidence in Karachi, Pakistan: First results from Karachi cancer registry. Int J Cancer. 2000; 85(3):325-9.

14. Roessler K, Dietrich W, Kitz K. High diagnostic accuracy of cytologic smears of central nervous system tumors. Acta Cytol. 2002; 46(4):667-74.

15. Shah AB, Muzumdar GA, Chitale AR, Bhagwati $\mathrm{SN}$. Squash preparation and frozen section in intraoperative diagnosis of central nervous system tumors. Acta Cytol. 1998; 42(5):1149-54.
16. Khoddami M, Akbarzadeh A, Mordai A, BidariZerehpoush F, Alipour H, Samadzadeh S, Alipour B. Diagnostic accuracy of frozen section of central nervous system lesions: A 10-year study. Iran J Child Neurol. 2015; 9(1):25-30.

17. Ud Din N, Memon A, Idress R, Ahmad Z, Hasan S. Central nervous system lesions: Correlation of intraoperative and final diagnoses, six year experience at a referral center in a developing country, Pakistan. Asian Pac J Cancer Prev. 2011; 12(6):1435-7.

\section{AUTHORSHIP AND CONTRIBUTION DECLARATION}

\begin{tabular}{|c|c|c|c|}
\hline Sr. \# & Author(s) Full Name & Contribution to the paper & Author(s) Signature \\
\hline 1 & Saad Akhter Khan & $\begin{array}{l}\text { Conception of study, } \\
\text { Designing / Planning. }\end{array}$ & \\
\hline 2 & Badar Uddin Ujjan & $\begin{array}{l}\text { Experimentation / Study } \\
\text { conduction. }\end{array}$ & \\
\hline 3 & Naveed Zaman Akhunzada & $\begin{array}{l}\text { Analysis / Interpretation / } \\
\text { Discussion. }\end{array}$ & \\
\hline 4 & Saad Bin Anis & $\begin{array}{l}\text { Manuscript writing / } \\
\text { Designing. }\end{array}$ & \\
\hline
\end{tabular}

